\title{
Insecticidal Activity of Essential Oil of Thymu Vulgaris on the Callosobruchus Maculatus
}

\author{
P.estekhdami $^{1^{*}}$, A. Nasiri Dehsorkhi ${ }^{2}$, R. Kalvandi ${ }^{3}$ \\ ${ }^{I}$ M.sc. Agronomy, Shahroud of University in Iran (2009). \\ ${ }^{2}$ Ph.D. student of Agroecology, Agronomy Department, Agricultural Faculty, University of Zabol, in Iran. \\ ${ }^{3} \mathrm{PhD}$ in Biology - Genetic, Academic member of Hamedan Agricultural and Natural Resources Research \\ Center.
}

*Corresponding Author: P.estekhdami, M.Sc. Agronomy, Shahroud of University in Iran (2008).

\begin{abstract}
Plant derived insecticides as compared to synthetic ones are safer for the environment, generally cost effective, easy to handle and used by small industries and farmers. an experiment was conducted on Hamedan Agricultural Research Center, , as factorial based on completely randomized blocks in 3 replications in 2009 during. Experimental treatments included 6 levels with concentration $(0,0.25,0$. $50,0.75,10,20,30) \mathrm{mg} / \mathrm{cm}^{2}$ as the time at 3 levels $(8,24,48)$ hours as the second factor. $1 \mathrm{ml}$ of each solution were applied on filter papers (Whatman No. 1). Then each dried paper was placed at the bottom of a Petri dish $(5.5 \mathrm{~cm} \times 1.2 \mathrm{~cm})$ and 10 adults each of $C$. maculatus was placed in each Petri dish and covered with a lid. Controls received only water alone. Each set of treatment was repeated 3 times and number of dead insects in each petri-dish was counted at an interval of $8,24,48$ hour respectively. Percentage mortality was calculated formula. The findings of contact toxicity unveiled that the mode of action of essential oil and its components against adults of $C$. maculatus was dosage and exposure time dependent. It has been noticed that the Thymu vulgaris essential oil showed $56 \%$ mortality adult C. maculatus at a dose of $0.25 \mathrm{mg} / \mathrm{cm}^{2}$ respectively. Further increase the concentration of oil to $30 \mathrm{mg} / \mathrm{cm}^{2}$, yielded higher mortality of $98 \%$ against adult C. maculatus. No mortality was obtained in the control within the same time period.
\end{abstract}

Keywords: Callosobruchus maculatus, Thymu vulgaris, Essential Oil

\section{INTRODUCTION}

Stored insect pests are a major problem throughout the world as they significantly reduce the quantity and quality of grain. The post-harvest grain losses due to insect pests and other bio-agents ranged from 10 to 40\% (Raja et al., 2001; Papachristos and Stamopoulos, 2002). It is evident from literature that the cowpea weevil, Callosobruchus maculatus (F.) and the rice weevil, Sitophilus oryzae (L.) are considered as the most widespread and destructive primary insect pests of stored legumes and cereals (Park et al., 2003). The main method of grain protection and to avoid or control insect infestations is the use of chemical agents since, it is the simplest and most cost effective means of dealing with stored product pests. But the excessive use of traditional chemical insecticides leads to a number of serious problems, like persistence in the atmosphere, resistance to chemical insecticides, pests resurgence, exclusion of economically beneficial insects, toxicity to humans and environment and higher cost of crop production. So, there is an urgent need to develop safe alternatives to conventional fumigants and insecticides to control the insect infestation in stored grain products. Continued screening for such systems of grain protection that target the pest species more accurately is required (Cox, 2004). Plant derived insecticides as compared to synthetic ones are safer for the environment, generally cost effective, easy to handle and used by small industries and farmers. Botanical pesticides are often active against a number of species, are often biodegradable, nontoxic and appropriate for use in integrated pest management (Kim et al., 2003). In this context, plant extracts including essential oils can play an important role in protecting stored products against insect infestations. Essential oils derived from plants are volatile in nature and their constituents have revealed adequate activity as botanical pesticides (Singh and Upadhyah, 1993). Spices are considered as rich sources of essential oils and are known to be effective against various insect pests including stored product insect pests (Jacobson, 1989). Clove oil was found toxic to S. oryzae and castor oil to C. maculatus and C. phaseoli in stored conditions. Fumigant toxicity of essential oils from several spices like anise 
(Pimpinella anisum L.) and peppermint (Mentha piperita L.) was found against four major stored product pests including, Ryzopertha dominica (F.), Tribolium castaneum (Herbst), S. oryzae and Orzyaephilus surinamensis (L.) (Shaaya et al., 1991). In this work, we have examined the activity of essential oil from Thymu vulgaris on the Callosobruchus.

\section{MATERIALS AND METHODS}

\subsection{Stock Culture}

The Callosobruchus maculatus (Fabricus) was used in the present investigation. A small population of beetles was reared and bred under laboratory conditions on the seeds of cowpea (Vigna unguiculata) inside a growth chamber at 30+20C, 12:12 L: D and with $70 \% \mathrm{RH}$.

\subsection{Plant Material}

Samples of Thymu vulgaris were collected during in May, 2009. The dried aerial parts were submitted to Hydro distillation for $3 \mathrm{~h}$ using Clevenger type apparatus, according to the European Pharmacopoeia (European Pharmacopoeia, 1996). The essential oil was collected, dried over anhydrous sodium sulphate and stored at $4^{\circ} \mathrm{C}$ until used.

\subsection{Mass Spectrometry Analysis}

The oil was analysed by gas chromatography-mass spectrometry (GC-MS) using a Hewlett Packard 6890 mass selective detector coupled with a Hewlett Packard 6890 gas chromatograph. The MS operating parameters were as follows: ionisation potential, $70 \mathrm{eV}$; ionisation current, $2 \mathrm{~A}$; ion source temperature, $200^{\circ} \mathrm{C}$, resolution, 1000 . Mass unit were monitored from 30 to $450 \mathrm{~m} / \mathrm{z}$. Identification of components in the oil was based on retention indices relatives to n-alkanes and computer matching with the WILLEY275.L library, as well as by comparison of the fragmentation patterns of mass spectra with those reported in the lite rapture (Adams, 1995).

\subsection{Contact Toxicity}

Insecticidal activities of essential oil of Thymu vulgaris adults of $C$. maculatus has been determined by direct contact application as cited in literature (Kim et al. 2003; Usha Rani 2010). Thymu vulgaris oil were prepared at concentrations of $\left(0.25,0.50,0.75,10,20,30 \mathrm{mg} / \mathrm{cm}^{2}\right)$ respectively. $1 \mathrm{ml}$ of each solution was applied on filter papers (Whatman No. 1). Then each dried paper was placed at the bottom of a Petri dish $(5.5 \mathrm{~cm} \times 1.2 \mathrm{~cm})$ and 10 adults each of $C$. maculatus was placed in each Petri dish and covered with a lid. Controls received only water alone. Each set of treatment was repeated 3 times and number of dead insects in each petri-dish was counted at an interval of 8, 24, 48 hour respectively. Percentage mortality was calculated formula.

\subsection{Statistics Analysis}

Statistical analysis was carried out using SAS software version 9.1 (SAS Institute Inc., Cary, NC, USA) and Comparing averages were carried out by one-way ANOVA using Duncan test.

\section{RESULTS}

\subsection{Chemical Composition of the Essential Oil}

Essential oil yield was $1.0 \%$. Freshly isolated essential oil was a yellow liquid with intensive, narcotic odour. The components of essential oil were separated into five classes, which were monoterpene hydrocarbons, oxygenated monoterpenes, sesquiterpene hydrocarbons, oxygenated sesquiterpenes and others . Based on GC and GC-MS analysis of the essential oil of Thymu vulgaris 40 components were identified. Among those, isospathulenol (21.68\%), $\alpha$-Humulene epoxide II (21.04\%), Caryophellene oxide (20.45\%), Spathulenol (20.42\%), Viridiflorene (18.34\%) were the major oil components (figure 1).

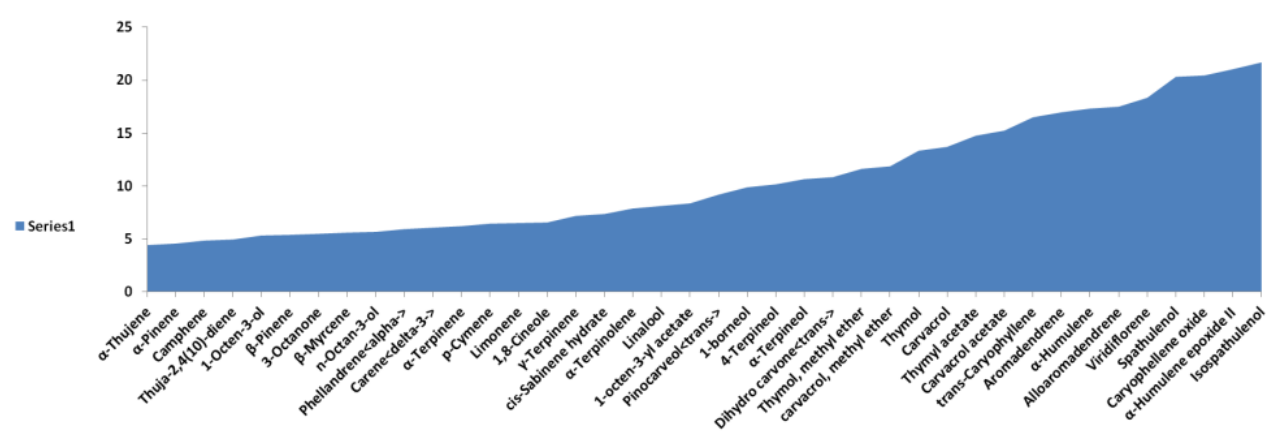

Figure1. Chemical composition of Thymus vulgaris $L$ 


\subsection{Contact Activity with Treated Filter Paper}

The results of comparing the means with Duncan's test indicated that there was a significant difference between different levels of essential oil of Thymu vulgaris with control (Table 1). The results of the analysis of variance showed that treatment of essential oil of Thymu vulgaris had significant effect on death rate of Callosobruchus maculatus at probability level of $1 \%$. Findings of essential oil the experiment indicated that the rate of losses of Callosobruchus maculatus had the lowest amount in all experiments in control treatment (no use of Thymu vulgaris essential oil). The findings of contact toxicity unveiled that the mode of action of essential oil and its components against adults of Callosobruchus maculatus was dosage and exposure time dependent. Concentrations $30 \mathrm{mg} / \mathrm{cm}^{2}$ the highest percentage of deaths. The highest effects were observed in 48 hours after adding the extract. The contact activity method has been widely used to investigate the toxicity of insecticides. The findings of contact toxicity unveiled that the mode of action of essential oil and its components against adults of $C$. maculatus was dosage and exposure time dependent. It has been noticed that the Thymu vulgaris essential oil showed 56\% mortality adult C. maculatus at a dose of $0.25 \mathrm{mg} / \mathrm{cm}^{2}$ respectively. Further increase the concentration of oil to 30 $\mathrm{mg} / \mathrm{cm}^{2}$, yielded higher mortality of $98 \%$ against adult C. maculatus. No mortality was obtained in the control within the same time period. Results in figure 2 showed strong toxicity the insect species than the Thymu vulgaris oil. In a test with C. maculatus adults, Thymu vulgaris at a dose of 30 $\mathrm{mg} / \mathrm{cm} 2$, caused 98 and $100 \%$ mortality at the time interval of 24 and 48 hour treatment respectively.

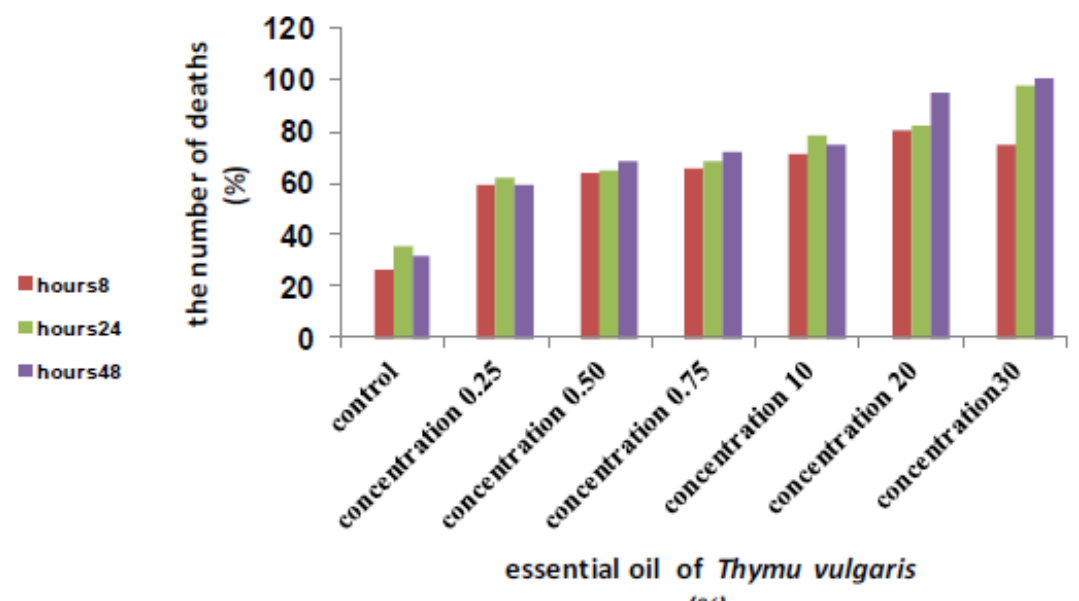

(\%)

Figure2. Compares the average the number of Insecticidal Activity of essential Oil of Thymu vulgaris on the Callosobruchus maculates

Table1. Analyze variance of data squares of Insecticidal Activity of essential Oil of Thymu vulgaris on the Callosobruchus maculatus

\begin{tabular}{|c|c|c|}
\hline S.O.V & Df & M s ( Number of losses) \\
\hline Replication & 2 & 12.81 \\
\hline Essential oil (A) & 6 & $53.54^{* *}$ \\
\hline hours (B) & 2 & $15.46^{* *}$ \\
\hline A $\times$ B & 12 & $305.45^{* *}$ \\
\hline Error & 40 & 10.12 \\
\hline \%CV & & 13.02 \\
\hline
\end{tabular}

\section{DISCUSSION}

Essential oil are natural products that contain natural flavors and fragrances grouped as monoterpenes (hydrocarbons and oxygenated derivatives), sesquiterpenes (hydrocarbons and oxygenated derivatives) and aliphatic compounds (alkanes, alkenes, ketones, aldehydes, acids and alcohols) that provide characteristic odors (Mahdi et al., 2011). Essential oil components and quality vary with geographical distribution, harvesting time, growing conditions and method of extraction (Yang et al., 2005). Among the essential oil components, the monoterpenoids have drawn the greatest attention for insecticidal activity against stored-product insects. Many essential oils isolated from various plant species belonging to different genera, contain relatively high amount of monoterpenes (Ogendo et al., 
2008). Monoterpenes are volatile and responsible for the characteristic odours of many plants. Their volatility which made them easy to discover in fragrant plant material and at the same time readily obtainable by simple distillation of plant parts, lent to them the essential oil (Ibrahim, 2001). These are easily degradable in soil and water (Misra and Pavlostathis, 1997). Previous studies have shown that the toxicity of essential oils obtained from aromatic plants against storage pests is related to the oil's main components (Isman et al., 2001; Lee et al., 2003) such as 1.8 Cineole, Carvacrol, Thymol, Eugenol, Terpinene, Limonene, $\alpha$-Pinene, among others. The essential oil of a plant may contain hundreds of different constituents but certain components will be present in larger quantities. 1,8cineole was predominant in the essential oils of Achillea millefolium (22\%), Artemisia aucheri (22.8\%), Eucalyptus camaldulensis $(69.46 \%)$, Eucalyptus globulus $(31.42 \%)$, Lavandula stoechas (48.5\%), Laurus nobilis (4.02) and Perovskia atriplicifolia (20.74). In recent years, several studies were reported on the toxicity of some essential oil constituents against various insect species. ObengOfori et al. (1997) found 1,8-cineole to be highly repellent and toxic to Sitophilus granarius L., S. zeamais, Tribolium confusum du Val and Prostephanus truncatus (Horn). Antifeedant activity of 1,8Cineole has been demonstrated against T. castaneum (Tripathi et al., 2001). Application of 1, 8Cineole reduced oviposition rate by $30-50 \%$ at concentration of $1.0 \%$, as compared to untreated controls (Koschier and Sedy, 2001). Lee et al. (2002) reported that 1,8-cineole was the most toxic fumigant constituent against the adults of Tribolium castaneum Herbst. In pest management strategies, aromatic plants with long lasting insecticidal efficiency should be considered. These considerations must take into account the pest species or the type of stored products. Large quantities of plant material would need to be processed to gain enough essential oil for commercial-scale tests. However, certain compounds in the oils exhibit much stronger activity than others. Plant varieties should be sought that produce these compounds in larger quantities, or synthetic production methods should be explored as an option to gain enough material for full-scale use. From the above discussion, it is clear that essential oils possess a wide spectrum of biological activity against insects and provides a simple and environment friendly (non-polluting and lesser or no toxicological concerns) alternative pest control. Since essential oils have strong toxicity in the vapour form against a wide range of insects, they could be commercially exploited as a fumigant for stored products and also impregnated into packaging thus preventing the insect infestation. However, the effects on other nontarget microorganisms including pollinators, honeybees and natural predators/enemies have not been yet evaluated. If the problem of cost-effective commercial production can be solved, some of the essential oils and their compounds could be find a place in IPM strategies, especially where the emphasis is on environmental and food safety and on replacing the more dangerous and toxic fumigants and insecticides.

\section{REFERENCES}

[1] Adams, R.P., 1995.Identification of Essential Oil Components by GC-MS. Allured Publication Corp., Carlo Stream, Il.

[2] Coxe, F. X., Abadie, C., Achard, R., Cattan, P., Chabrier, C., and Tixier, P., 2004. Integrated pest management approaches developed in the French West Indies to reduce pesticide use in banana production systems. Acta Hort. 828: 375-382.

[3] European pharmacopoeia. 5 ed. Strasbourg: Council of Europe: E.P.C.; 2004. pp. 217-218.

[4] Huignard, J., 1998Importance des pertes dues aux insectes ravageurs des graines: problèmes posés par laconservation des légumineuses alimentaires, sources de protéines végétales. Cah.Nutr Diet; 20:193-200.

[5] Ibrahim, M.A., 2001. Insecticidal, repellent, antimicrobial activity and phyto toxicity of essential oils: with special reference to limonene and its suitability for control of insect pests. Agric. Food Sci., 10: 243-259.

[6] Isman, M.B., Wan, A.J., and Passreiter, C.M., 2001. Insectical activity of essential oils to the tobacco cutworm, Spodoptera litura. Fitoterapia, 72: 65-68.

[7] Jacobsen, C. S., 1989. Agricultural soils, pesticides and microbial diversity. Curr. Opin. Biotechnol. 27: 15-20 .

[8] Kim, D. H., and Ahn, Y. J., 2003. Contact and fumigant activities of constituents of Foeniculum vulgare fruit against three Coleopteran stored-product insects. Pest Management Science. 57:301-306.

[9] Koschier, E.L., and Sedy, K.A., 2001. Effects of plant volatiles on the feeding and oviposition of Thrips tabaci. In: Thrips and Tospoviruses, Marullo, R. and L. Mound (Eds.). CSIRO, Australia, pp: 185-187.

[10] Lee, S., Peterson, C.J., and Coats, J.R., 2002. Fumigation toxicity of monoterpenoids to several stored product insects. J. Stored Prod. Res., 39: 77-85

[11] Lee, S. E,, Peterson, C. J., and Coats, J. R., 2003. Fumigation toxicity of monoterpenoids to several stored product insects. Journal of Stored Products Research. 39:77-85. 
[12] Mahdi, S.K., J. Sasan and K. Sara, 2011. Contact toxicities of oxygenated monoterpenes to different populations of colorado potato beetle, Leptinotarsa decemlineata Say (Coleoptera: Chrysomelidae). J. Plant Prot. Res., 51: 225-233.

[13] Misra, G. and S.G. Pavlostathis, 1997. Biodegradation kinetics of monoterpenes in liquid and soil-slurry systems. Applied Microbiol. Biotechnol., 47: 572-577.

[14] Obeng-Ofori, D., Reichmuth, C.H., Bekele, J., and Hassanali, A., 1997. Biological activity of 1,8 cineole, a major component of essential oil of Ocimum kenyense (Ayobaugira) against stored product beetles. J. Applied Entomol., 121: 237-2.

[15] Ogendo, J.O., Kostyukovsky, M., Ravid, U., Matasyoh, J.C., and Deng, A.L., et al., 2008. Bioactivity of Ocimum gratissimum L. oil and two of its constituents against five insect pests attacking stored food products. J. Stored Prod. Res., 44: 328-33.

[16] Papachristos, D.P., and Stamopoulos, D.C., 2002. Fumigant toxicity of three essential oils on the eggs of Acanthoscelides obtectus (Say) (Coleoptera: Bruchidae). J. Stored Prod. Res., 40: 517-525.

[17] Prak, A., Bentur, J. S., Prasad, M. S., Tanwar, R. K., Sharma, O. P., Bhagat, S., et al. 2003. Integrated Pest Management for Rice. New Delhi: IARI campus: National centre for integrated pest management. 43.

[18] Raja, N., Albert, S., Ignacimuthu S., and Dorn. S., 2001. Effect of plant volatile oils in protecting stored cowpea Vigna unguiculata (L.) Walpers against Callosobru- chus maculatus (F.) (Coleoptera: Bruchidae) infestation. J. Stored Prod. Res. 37: 127-132.

[19] Singh, R., and Ellis, P. R., 1993. Sources, mechanisms and bases of resistance in cruciferae to the cabbage aphid, Brevicoryne brassicas. International Organization of Biological and Integrated Control of Noxious Animals and Plants/West Palaeartic Regional Section Bulletin, Darmstadt, 16 (5): 21-35.

[20] Shaaya, E., U. Ravid, N. Paster, B. Juven, U. Zisman and V. Pissarev, 1991. Fumigant toxicity of essential oils against four major stored-product insects. J. Chem. Ecol., 17: 499-504.

[21] Tripathi, A.K., V. Prajapati, K.K. Aggarwal and S. Kumar, 2001. Toxicity, feeding deterrence and effect of activity of 1,8,-Cineole from Artemisia annua on progeny production of Tribolium castaneum (Coleoptera: Tenebrionidae). J. Econ. Entomol., 94: 979-983 .

[22] Yang, P., Y. Ma and S. Zheng, 2005. Adulticidal activity of five essential oils against Culex pipiens Quinquefasciatus. J. Pestic. Sci., 30: 84-89.

Citation: P. Estekhdami, "Insecticidal Activity of Essential Oil of Thymu Vulgaris on the Callosobruchus Maculatus" International Journal of Research Studies in Agricultural Sciences (IJRSAS), 2019; 5(8), pp. 2630, http://dx.doi.org/10.20431/2454-6224.0508004

Copyright: (C) 2019 Authors. This is an open-access article distributed under the terms of the Creative Commons Attribution License, which permits unrestricted use, distribution, and reproduction in any medium, provided the original author and source are credited. 